\title{
NEGLIGIBLE FORCHHEIMER EFFECT FOR A MAXIMUM GAS FLOW RATE IN A GAS CONDENSATE RESERVOIR
}

Enoc Basilio Meza $^{1 *}$; William Navarro Cornejo ${ }^{2}$

*A quien debe dirigirse la correspondencia

\begin{abstract}
In this paper the optimal gas flow rate in a retrograde gas condensate reservoir has been calculated in order to minimize retrograde condensation, maximizing the slip velocity, due to the positive coupling effect; and minimizing the pressure drawdown, due to the Forchheimer effect (non-Darcy effect, inertial effect). Non-Darcy behavior has been thoroughly described because of its importance for describing additional pressure drawdown (more than expected by Darcy equation) in fluid flow in porous media, in situations where high velocity occurs. The coupling effect explains the increment of the gas-condensate relative permeability with increasing velocity and decreasing the interfacial tension. The Forchheimer equation has been used to calculate the bottom-hole flowing pressure for different gas flow rates. Because of the second term in the Forchheimer equation, which is function of the square of the superficial velocity of the fluid, this obtained value is less than the bottom-hole flowing pressure obtained from Darcy equation. This is important because a higher quantity of condensate liquids is obtained, which reduces the relative permeability, and as a result, the gas flow rate decreases due to this effect. For those different gas flow rates, the optimal gas flow rate, where the bottom-hole flowing pressure is acceptable, has been found. The novelty of the present work, is to present the optimal point where the gas flow rate is maximum, in which the non-Darcy effect is negligible.
\end{abstract}

Keywords: Forchheimer effect, Coupling effect, Gas Condensate Reservoir

\section{EFECTO FORCHHEIMER DESPRECIABLE PARA UN CAUDAL DE GAS MÁXIMO EN UN YACIMIENTO DE GAS CONDENSADO}

\section{RESUMEN}

En el presente trabajo se calcula el caudal óptimo de gas de un yacimiento de gas condensado retrógrado, con el objetivo de reducir la condensacion retrógrada, maximizando la velocidad de arrastre debido al efecto coupling y minimizando la caída de presión debido al efecto Forchheimer (efecto no-Darcy, efecto inircial). El comportamiento inercial ha sido estudiado ampliamente debido a su importancia en describir la caida de presión adicional (más de la esperada de acuerdo a la ecuación de Darcy) en el flujo de fluidos en medios porosos, en situaciones de gran velocidad. El efecto de acoplamiento, explica el incremento de la permeabilidad relativa de gas condensado al incrementar la velocidad y disminuir la tensión interfacial. La ecuación de Forchheimer se utilizó para calcular la presión de fondo fluyente a diferentes caudales. Debido al segundo término en la ecuación de Forchheimer, la cual es función del cuadrado de la velocidad superficial del fluido, este valor obtenido resulta siendo menor a la presión de fondo fluyente obtenida mediante la ecuación de Darcy. Esto es importante pues se acumula una cantidad mayor de líquidos, lo cual reduce la permeabilidad relativa, y como consecuencia, el caudal de gas disminuye. Para los caudales de gas propuestos, se encuentra el caudal de gas óptimo, la cual es aquella donde la presión de fondo fluyente es aceptable. La novedad del presente trabajo, es la presentación de un punto óptimo, en el cual el caudal de gas es máximo, para el cual el efecto inercial es despreciable en comparación con el efecto coupling.

Palabras clave: Efecto Forchheimer, Efecto Coupling, Yacimiento de Gas Condensado

1. Departamento de Ingeniería de Petróleo y Gas Natural, Facultad de Ingeniería de Petróleo, Gas Natural y Petroquímica, Universidad Nacional de Ingeniería, UNI, Av. Túpac Amaru s/n - Oficina de Posgrado de la Facultad de Ingeniería de Petróleo, Gas Natural y Petroquímica, Rimac, Lima 25, Lima, Perú.

2. Departamento de Ingeniería de Petróleo y Gas Natural, Facultad de Ingeniería de Petróleo, Gas Natural y Petroquímica, Universidad Nacional de Ingeniería, UNI, Av. Túpac Amaru s/n - Oficina de Posgrado de la Facultad de Ingeniería de Petróleo, Gas Natural y Petroquímica, Rimac, Lima 25, Lima, Perú. 


\section{INTRODUCTION}

Gas condensate reservoirs have been classified between volatile oil and wet gas reservoirs. It means, the reservoir temperature is between the critical temperature and the cricondentherm. A gas condensate is a single-phase fluid at original reservoir conditions but it becomes on a two fluid system as pressure drops below dew point. The behavior of gas condensate reservoirs is not fully understood, because of their complexity owing to the presence of a two fluid system, gas-phase and liquid-phase (Economides et al., 1987; Bloom, 1998; Yu, 1996; Gondouin, 1967) and they are becoming more common as the exploration for oil and gas are being targeted on deeper depths, higher pressures, and higher temperatures. The behaviors of such systems are complex, especially in the near-wellbore region, where a high-velocity occurs (Gringarten et al., 2006). It is known that gas contracts are signed at the beginning of the development of the field and it usually takes a long period of time (e.g. 40 years in Peru). It is important to get a better understanding that leads us to accurate predictions of well deliverability for selecting the best development plan (Mott et al., 2000), and to avoid problems like non-reversible reduction in well productivity, having a less marketable gas, and not to meeting contractual obligations of gas sales.

Great efforts have been exerted into getting an accurate calculation of gas-condensate well deliverability and therefore, a better understanding of its flow behavior. Among many researchers, Fevang \& Whitson, (1996); Ali et al., (1997); and Kalaydjian et al., (1996), have found the existence of three flow regions with different liquid saturations when retrograde condensation occurs, caused by the pressure drop below dew point in the wellbore vicinity. Figure 1 shows the three regions of flow behavior in a gas-condensate well, conceptually proposed by Fevang \& Whitson, (1996): (1) an inner near wellbore region where both gas and condensates flow simultaneously (at different velocities), because the condensate saturation is greater than the critical condensate saturation; (2) a region of condensate buildup, where the liquid saturation remains below the critical saturation, which is practically immobile, thus only gas is flowing; and (3) a region containing singlephase (original) reservoir gas, because the reservoir pressure is above the dewpoint.

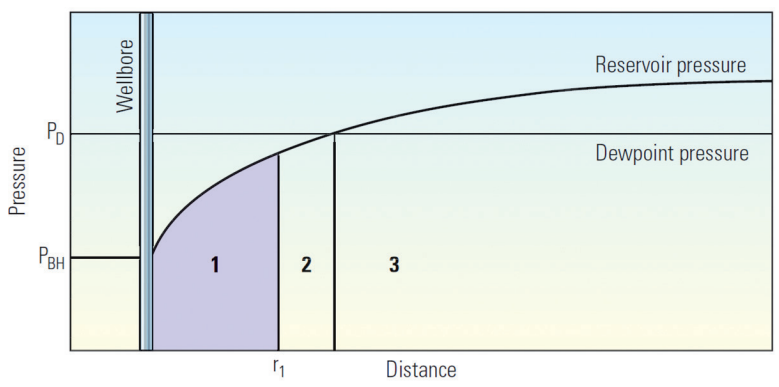

Figure 1. Three regions of reservoir flow behavior. Source: Pope et al. (2006)

Among the aforementioned three regions, regions (1) and (2) have a special importance, because these regions may affect well deliverability and producing wellstream composition, causing production loss and a leaner composition, respectively. Region 1 is very important, because extreme conditions of velocity occur which are determined by inertial forces resulting from convective acceleration of fluid particles in the medium, in addition to viscous forces (Sheikhi et al., 2015) and they affect the relative permeability which is reduced due to condensate buildup. This phenomenon is known as the Forchheimer effect (non-Darcy effect, inertial effect). However, Danesh et al., (1994), observed that when Forchheimer effect was not significant, the relative permeability of condensing systems, increased with increasing velocity, as well as that caused by a reduction in interfacial tension. Afterwards, Henderson et al., (2000), concluded that the relative permeability at low interfacial tension (IFT) decreased with increasing velocity at low condensate saturations and, increased with increasing velocity or decreasing IFT at high condensate saturations. This phenomenon was later called the "positive coupling effect", because of the coupling of the flow of the gas and condensate phase, at high velocities. Finally, Jamiolahmady et al., (2009) reported that for these high condensate saturations, the positive coupling effect surpasses the inertial effect, resulting in a net increase of relative permeability. Region 2 is also important because the original gas-phase loses its valuable components due to the accumulation of condensate, and they cannot be easily recovered because the mobility of the condensate is very 
small (practically zero). Throughout the production, the size of Region 1 increases and consequently, the size of Region 2 decreases.

For explaining this phenomenon, many authors have referred to Afidick et al. (1994), who studied the Arun field, located in North Sumatra, Indonesia, where the production had a significant loss in well deliverability after 10 years of continuous production. Well studies, indicated that the loss was caused by near wellbore condensate accumulation. They showed that liquid dropout does not have a significant effect on the flow of fluids in the reservoir, but it causes a severe restriction of the gas flow in the immediate region around the wellbore, affecting the productivity index by $50 \%$, even when it is a fairly lean gas reservoir.

This paper presents a methodology to analyze the Forchheimer effect and to observe the competition between inertial and coupling effects in the Pagoreni Field, which is a lean gas condensate field. The inflow performance relationship (IPR) for well \#7, which is the most productive and richest well in the main reservoir of the Pagoreni field, will be shown considering two scenarios: (1) an IPR under the Darcy approach, (2) an IPR under the Forchheimer approach. The huge quantity of gas flow rate loss, can be incremented to an optimal point through maximizing the slip velocity. Gas relative permeability for the inertial and coupling effects show that it is possible to increase the slip velocity as liquid dropout is being increased. Maximizing the slip velocity does not mean "wasting" the reservoir energy, but to optimize it at a point that might be acceptable. The IPR curves and the pressure profile around the wellbore show that an optimal pressure drawdown can be reached without "draining" the reservoir at a low FBHP.

The main objective of the present work is to demonstrate that gas well deliverability can be underestimated if only the non-Darcy effect is considered. In a context where a competition between Forchheimer and coupling effects is observed, the optimal point where the gas flow rate is maximum, is presented, in which the pressure drawdown is considered to be acceptable, and the Forchheimer effect can be considered negligible. The optimal gas flow rate is an alternative to operational conditions in order to reach a critical velocity to carry up the liquid droplets to the surface but no surpass the limiting velocity which can cause a well string erosion.

\section{THEORETICAL BACKGROUND}

The basic law governing the flow of fluids through porous media is Darcy's law, which was formulated on the basis of Darcy's experiments on vertical water filtration. Darcy's law describes a linear relationship between volumetric flow rate (Darcy velocity) and pressure gradient (Muskat, 1946). The one-dimensional Darcy equation can be written as:

$$
-\frac{d p}{d L}=\frac{\mu v}{k}
$$

where $\mu$ is the fluid viscosity, $\mathrm{k}$ is the permeability and $\mathrm{v}$ is the superficial velocity of the fluid, as defined by the following equation:

$$
v=\frac{q}{2 \pi r h}
$$

Even though Darcy's law is thoroughly used when describing fluid flow through porous media, there is considerable evidence that Darcy's law is inadequate for representing high-velocity fluid flow in porous media, such as near the wellbore. When correlating the data for high-velocity water flow through porous media, Forchheimer (1901) found that the relationship between pressure gradient and fluid velocity was no longer linear, as described by linear Darcy's flow. Forchheimer found that his data were better described as a relationship of the form:

$$
-\frac{d p}{d L}=\frac{\mu v}{k}+\beta \rho v^{2}
$$

In the latter equation, the first term in the right hand side is the Darcy or viscous component while the second term is the high-velocity or non-Darcy component in which $\beta$ is called the non-Darcy velocity coefficient. Forchheimer effect, also known as non-Darcy effect or inertial effect, has been thoroughly described in technical literature (Fancher et al., 1933; Geertsma, 1974; Katz and Lee, 1990) because of its importance for describing additional pressure drawdown due to high fluid flow rates. The non-Darcy effect appears in welldeliverability equations as a flow-rate-dependent skin:

$$
s^{\prime}=s+D q
$$


Where D is called the non-Darcy-flow coefficient, and it may be calculated from laboratory measurements or from well tests. The flow of gas in porous media considering the non-Darcy conditions is then expressed as (Economides, 1994):

$$
q=\frac{k_{g} h\left[m(\bar{p})-m\left(p_{w f}\right)\right]}{1424\left[\operatorname{In}\left(\frac{0,472 r_{e}}{r_{w}}\right)+s+D q\right]}
$$

Thepseudopressureapproach has beenused hereforbeing widely utilized in mathematical modeling of IPR of gas wells because it is considered to be a "pseudoproperty" of gas. Determining the pseudopressure at a given pressure requires knowledge of gas viscosity and z-factor as functions of pressure and temperature (Guo $\&$ Ghalambor 2005). The parameter $\beta$ is very important when applying Forchheimer's equation, for that reason, many methods have been developed to calculate $\beta$. They are based on experimental work, correlations, and an alternative algebraic form of Eq. 3, where a Cartesian plot of $\Delta m / q_{g}$ vs. $q_{g}$ will result in a straight line of slope of $b$ and an intercept of $a$. This algebraic form will be used in the present paper, because its variables are based on reservoir and well properties.

$$
\Delta m=m(\bar{p})-m\left(p_{w f}\right)=a q+b q,
$$

where,

$$
\begin{gathered}
a=\frac{\beta}{k h}\left[\operatorname{In}\left(\frac{r_{e}}{r_{w}}\right)+s\right] \\
b=\frac{\beta}{k h}(D)
\end{gathered}
$$

As described before, the most important parameter for determining the impact of condensate blockage and the benefit of the coupling effect is the effective gas permeability (expressed as the gas relative permeability) in the vicinity of the well (Mott et al., 2000). Thus, the simplest definition of gas relative permeability is as follows:

$$
k_{r g}=\frac{k_{g}}{k}
$$

\section{RESERVOIR DESCRIPTION}

The Pagoreni field, which is part of the great Camisea gas-condensate project, was discovered in 1998. It is one of the largest gas condensate fields in Peru, and is located in the Cuzco region, where the most important Peruvian gas condensate reservoirs are located. It is noteworthy that the conforming reservoirs in the Camisea gascondensate project are lean gas condensate reservoirs. Geologically, the Pagoreni structure is an elongated and folded anticline situated in the sub-Andean folded belt of the southern Ucayali Basin (Navarro \& Jamiolahmady, 2014).

Reservoir rock properties. The rock and well properties are summarized in Table 1 . The pay zone thickness is approximately 72.25 feet, which shows an average porosity of $14.5 \%$. In the entire range of the pay zone thickness, permeability presents values from $0.1 \mathrm{md}$ to $286 \mathrm{md}$, in this study a representative average permeability of $77.5 \mathrm{md}$ will be considered. For describing rock and fluid properties, the endpoints of relative permeability tests for the systems oil-water and gas-liquid, have been taken. Corey's method (Corey, 1954) has been used for generating the relative permeability curves, with an exponent 3 which represents the productive sands of the Pagoreni field. It is noteworthy that the aforementioned curves, represent to the base relative permeability curves, in which neither the Forchheimer nor coupling effects have been taken into account. The two-phase oil/water at $S_{g}-0$ and gas/ liquid base relative permeability curves are shown in Figure 2 and Figure 3 respectively.

Table 1. General rock properties of the Pagoreni field

\begin{tabular}{|cc|}
\hline Property & Value \\
\hline Effective gas permeability & $77.5 \mathrm{md}$ \\
\hline Porosity & 0.145 \\
\hline Pay zone thickness & $72.25 \mathrm{ft}$ \\
\hline Equivalent drainage radius & $1490 \mathrm{ft}$ \\
\hline Wellbore radius & $0.708 \mathrm{ft}$ \\
\hline Darcy skin factor & 7.4 \\
\hline Non-Darcy coefficient & $0.0000588 \mathrm{~d} / \mathrm{Mscf}$ \\
\hline Reservoir Pressure & $3500 \mathrm{psia}$ \\
\hline Reservoir Temperature & $180{ }^{\circ} \mathrm{F}$ \\
\hline Gas specific gravity & $0.65(1 \mathrm{for}$ air $)$ \\
\hline Connate water saturation & $22.7 \%$ \\
\hline
\end{tabular}




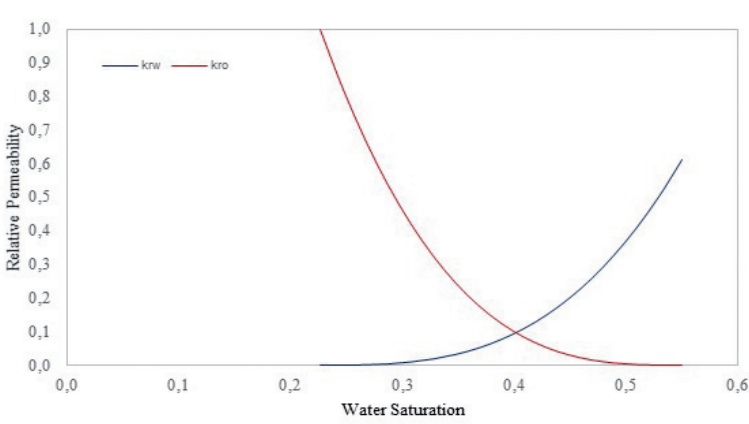

Figure 2. Oil/water relative permeability curve

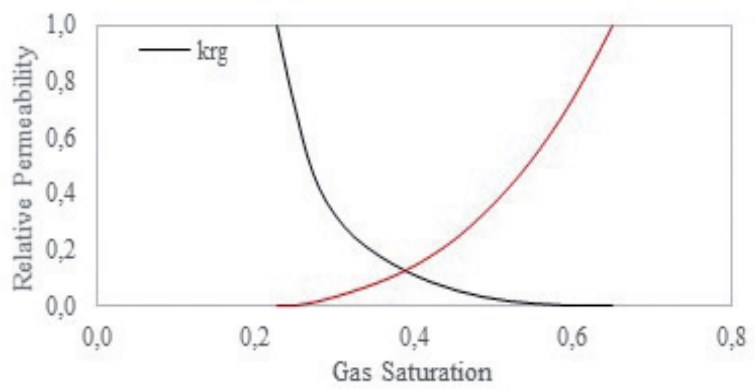

Figure 3. Gas/oil relative permeability curve.

Reservoir fluid description. Standard PVT measurements were performed to determine the dew point pressure and liquid dropouts in constant composition expansion (CCE) and constant volume depletion (CVD) at the reservoir temperature $\left(180^{\circ} \mathrm{F}\right)$. Figure 4 and Figure 5 show calculated and laboratory observed data for different parameters in the CVD and CCE measurements respectively. Table 2 illustrates the specific characterization of the reservoir fluid.

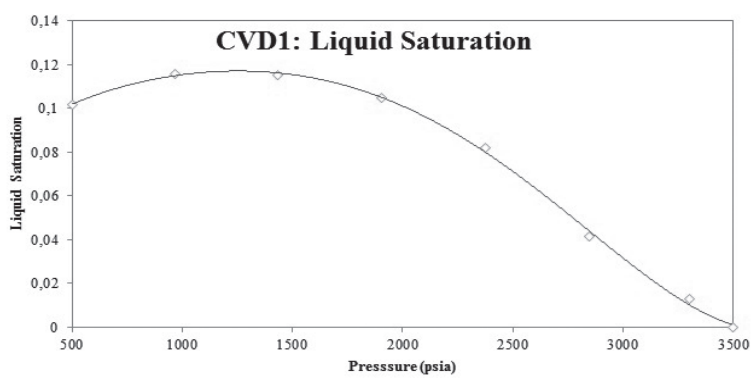

Figure 4. Experimentally measured condensate saturation vs. pressure during CVD.

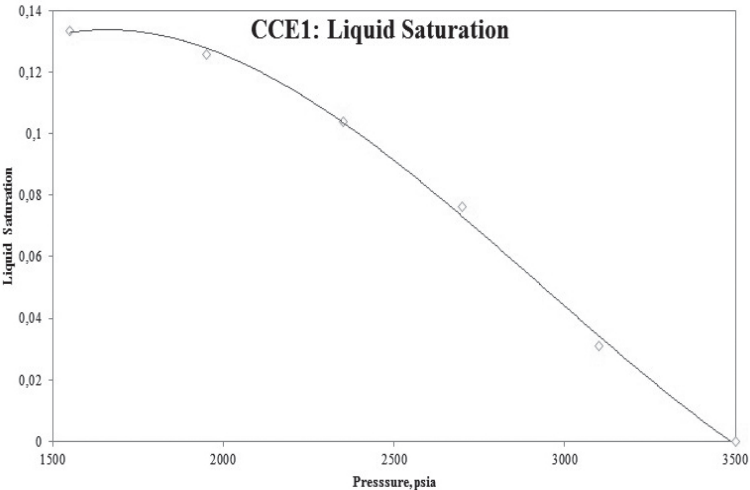

Figure 5. Experimentally measured condensate saturation vs. pressure during $\mathrm{CCE}$

Table 2. Some fluid characteristics

\begin{tabular}{cc} 
Property & Value \\
\hline Dew point pressure & $3472 \mathrm{psia}$ \\
\hline Reservoir temperature & $180^{\circ} \mathrm{F}$ \\
CGR & $40 \mathrm{bbl} / \mathrm{MMscf}$ \\
\hline $\begin{array}{c}\text { Maximum condensate saturation } \\
\text { from CVD test }\end{array}$ & $11.6 \%$ \\
\hline
\end{tabular}

\section{METHODOLOGY}

For analyzing the Forchheimer effect in a context where a rivalry exists between the inertial and coupling effects, well \#7, which is vertical and one of the "richest" wells in the Pagoreni field, has been chosen. A graphical representation of the relationship that exists between the gas flow rate and the FBHP was constructed for the selected well by using Eq. (5). This relationship is called the inflow performance relationship (IPR). The IPR curve for the selected well is shown in Figure 6. In this IPR curve, the blue line represents the theoretical behavior, hence the near wellbore effects are not considered and thus the gas flow is considered to be under the Darcy flow regime. The red line do takes the near-wellbore effects, in this case, as the reservoir is working with a FBHP below dewpoint, it is right to suppose that the well is working under the nonDarcy flow regime, where Eq. (1) is not applicable, as represented in the $v$ vs. $\left(\Delta p=p_{r}-p_{w f}\right)$ plot in Figure 7, but Eq. (2) does. 


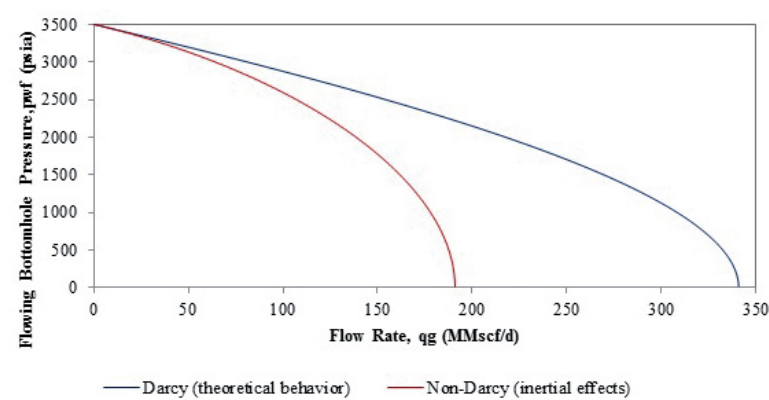

Figure 6. Inflow performance relationship (IPR) the well \#7.

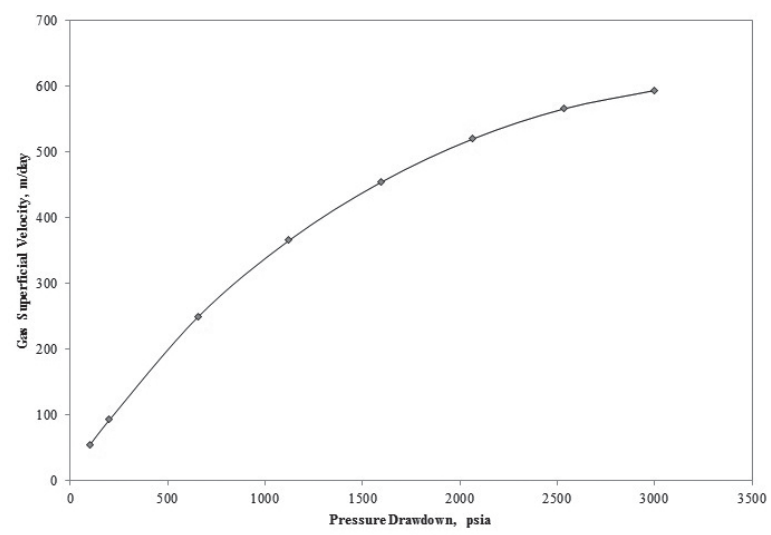

Figure 7. Effect of high-velocity flow on Darcy's equation.

The non-Darcy-flow coefficient, D, was obtained by analyzing well test data of the well \#7. The non-Darcy velocity coefficient, $\beta$, was determined by applying Eq. (6) relationships, after constructing the Cartesian plot of $\Delta m / q_{g}$ vs. $q_{g}$, and adjusting the plots to a straight line by the least square method as it is illustrated in Figure 8 . The gas relative permeability data at low IFT $(0.015$ $\mathrm{mNm}^{-1}$ ), which depends on the condensate saturation and the fluid velocity, used in the present study is shown in Figure 9. These data were obtained from the work of Jamiolahmady et al., (2003). These data are a reliable source for studying the Pagoreni field, because the permeability of the core sample used by the authors is $92 \mathrm{mD}$ at $S_{w c}=26.4 \%$ while the rock permeability in the present study is $77.5 \mathrm{mD}$ at $S_{w c}=22.7 \%$. Furthermore, the core sample used by the authors has similar characteristics in rock composition with the most important reservoir in the Pagoreni Field, where well \#7 is located. Thus, there is a close relationship that will allows us to get acceptable results.

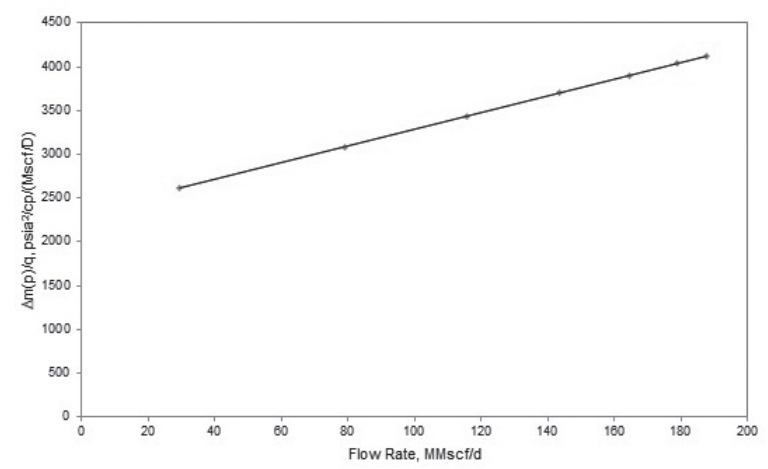

Figure 8. Theoretical gas-wellstabilized-deliverability plot.

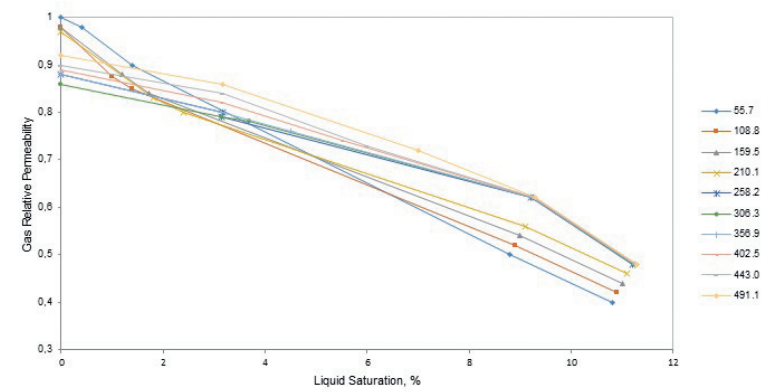

Figure 9.-Gas relative permeability for the Berea core sample measured in the 3D pore network model simulator. Source: (Jamiolahmady et al., 2009)

When the flow velocity drops to below a critical velocity at which the liquid droplets cannot be carried up to surface by gas, annular flow or even slug flow may develop in the well. For this reason, the critical velocity $(Q c)$ of the well \#7 is $30 \mathrm{MMscf} / \mathrm{d}$. But it is also essential not to surpass the limiting flow velocity, which is the capacity of the production string. The limiting velocity $\left(Q_{l}\right)$ for the well \#7 is from 90 to $110 \mathrm{MMscf} / \mathrm{d}$.

Based on the information of the preceding paragraphs, 9 FBHPs have been selected in order to get a more practical and accurate result. For each FBHP, both the gas flow rate under the Darcy flow regime and the gas flow rate under the Forchheimer effect have been calculated. From Figure 9, the gas relative permeability as a function of the superficial velocity and the liquid saturation (obtained from the PVT data at CVD) was obtained. Since the Forchheimer effect has been observed, it is necessary now, to consider the existence of the coupling effect looking for an optimal flow rate that 
can maximize the velocity slip. Thus, in a context where a competition exists between Forchheimer and coupling effects, the optimal point, where the gas flow rate is considered to be maximum, will be the one in which the energy loss (presented here as pressure drawdown) is acceptable in order to get a greater and optimal gas flow rate avoiding the formation of condensate buildup of many feet of radius.

\section{RESULTS AND DISCUSSION}

The presented IPR curves, show the huge difference existing in well deliverability when the non-Darcy effects are not taken into account. The theoretical flow shows an AOF of $341 \mathrm{MMscf} / \mathrm{d}$ when no inertial effects are considered, but when the negative inertial effect is taken into account, the $\mathrm{AOF}$ is reduced to an $\mathrm{AOF}$ of $191 \mathrm{MMscf} / \mathrm{d}$. It means a vast reduction of $44 \%$ in well deliverability. Figure 3 shows a base critical liquid saturation of $25.3 \%$ which signifies that a liquid saturation greater than $25.3 \%$, to observe the condensate mobility, is necessary. Since interstitial water saturation is $22.7 \%$, the condensate saturation has to be greater than $3 \%$ for observing condensate mobility.

Table 3 shows the results of the gas flow rate under Darcy behavior, non-Darcy behavior and the coupling and non-Darcy effect competition, for the gas flow rates within the $Q c$ and the $Q_{l}$ each one for the selected FBHPs. As predicted before, the values of condensate saturation that are less than 3\%, do not cause any improvement in the gas flow rate. The gas relative permeability when the gas flow rate is under the non-Darcy effect, has been calculated by applying Eq. (7). For determining the gas relative permeability when coupling effect is acting, Figure 9 has been used as explained before.

Table 3. Results of the proposed methodology

\begin{tabular}{|c|c|c|c|c|c|c|c|c|c|}
\hline LDO & $\begin{array}{l}\text { Velocity } \\
\text { (m/day) }\end{array}$ & $\begin{array}{l}\text { Gas Flow } \\
\text { Rate } \\
\text { Theoretical } \\
\text { (MMscf/d) }\end{array}$ & $\begin{array}{c}\text { Gas Flow } \\
\text { Rate } \\
\text { Inertial effect } \\
\text { (MMscf/d) }\end{array}$ & $\begin{array}{l}\text { Gas Flow Rate } \\
\text { Coupling effect } \\
\text { and Inertial } \\
\text { effect } \\
\text { (MMscf/d) }\end{array}$ & $\begin{array}{l}\text { Pressure } \\
\text { Drawdown } \\
\text { (psia) }\end{array}$ & Coupling & $\begin{array}{l}\text { Non- } \\
\text { Darcy }\end{array}$ & Effect & $\begin{array}{c}\text { Additional } \\
\text { Gas Flow } \\
\text { Rate } \\
\text { (MMscf/d) }\end{array}$ \\
\hline $7.16 \%$ & 491.1 & 155.2 & 107.2 & 111.7 & 1000 & 0.72 & 0.69 & Slipping & 4.5 \\
\hline $6.41 \%$ & 443.0 & 140.0 & 100.0 & 102.2 & 900 & 0.73 & 0.71 & Slipping & 2.2 \\
\hline $5.58 \%$ & 402.5 & 127.2 & 92.0 & 94.1 & 800 & 0.74 & 0.72 & Slipping & 2.1 \\
\hline $4.72 \%$ & 356.9 & 112.8 & 84.0 & 85.7 & 700 & 0.76 & 0.74 & Slipping & 1.7 \\
\hline $3.96 \%$ & 306.3 & 96.8 & 74.4 & 75.5 & 600 & 0.78 & 0.77 & Slipping & 1.1 \\
\hline $3.17 \%$ & 258.2 & 81.6 & 64.0 & 64.5 & 500 & 0.79 & 0.78 & Slipping & 0.5 \\
\hline $2.45 \%$ & 210.1 & 66.4 & 54.4 & 53.1 & 400 & 0.80 & 0.82 & $\begin{array}{c}\text { No } \\
\text { Slipping }\end{array}$ & -1.3 \\
\hline $1.73 \%$ & 159.5 & 50.4 & 43.2 & 42.3 & 300 & 0.84 & 0.86 & $\begin{array}{c}\text { No } \\
\text { Slipping }\end{array}$ & -0.9 \\
\hline $1.08 \%$ & 108.8 & 34.4 & 30.4 & 30.1 & 200 & 0.88 & 0.88 & $\begin{array}{c}\text { No } \\
\text { Slipping }\end{array}$ & -0.3 \\
\hline
\end{tabular}

From a simple point of view, it looks like the optimal gas flow rate is $111.7 \mathrm{MMscf} / \mathrm{d}$ because it has the highest additional gas flow rate. However, according to the pressure profile shown in Figure 10, it can cause a pressure drawdown of $1000 \mathrm{psi}$ and, as a consequence, a condensate buildup of a radius of more than $400 \mathrm{ft}$ will be formed. Also, as mentioned before, this well has a limiting velocity (maximum velocity in which there will not be well string erosion) from $90-110 \mathrm{MMscf} / \mathrm{d}$. Finally, according to Figure 6 and Figure 10 it can be seen that in a range of $64-85 \mathrm{MMscf} / \mathrm{d}$ an optimal point can be reached, generating an increment in the gas flow rate from $0.5-2 \mathrm{MMscf} / \mathrm{d}$ and an acceptable pressure drawdown in a range of $500-700$ psia and a condensate buildup with radii between 50 and $200 \mathrm{ft}$. This range in the gas flow rate express an equilibrium between superficial velocity and condensate buildup formation, in which the radii of the condensate buildup at a pressure drawdown of $500-700 \mathrm{psi}$ do not generate a significant damage (reduction) in the well production. 


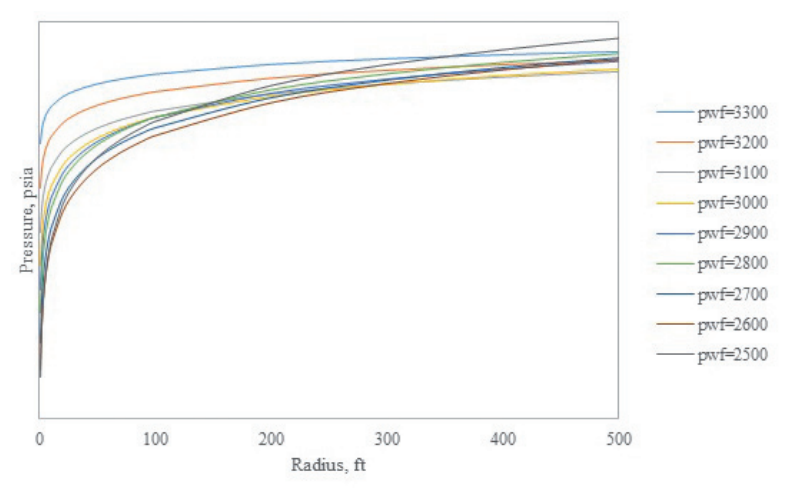

Figure 10. Pressure profile around the near wellbore region for well \#7.

\section{CONCLUSIONS}

- Even though the reservoir studied is a lean gas condensate reservoir, it is affected by the condensate banking phenomena, in which the coupling effect becomes more important as liquid saturation and velocity are increased.

- Well deliverability can be underestimated when taking into account inertial effects only. Results have shown an improvement in the well deliverability when coupling effect is considered at low interfacial tension (IFT).

- Forchheimer effect becomes negligible when producing at high flow rates in a well where the condensate saturation is good enough for the slip velocity to operate.

- For this lean gas reservoir, the optimal gas flow rate has been found, in which the pressure drawdown is acceptable, avoiding unnecessary loss of the energy (pressure) from the reservoir, and recovering the optimal quantity of gas and condensates.

- The optimal point for optimizing the Pagoreni Field production is from 64 to $85 \mathrm{MMscf} / \mathrm{d}$ which greatly reduces the negative effect of the Forchheimer effect and causes an increment of the gas flow rate in a range of $0.5-2 \mathrm{MMscf} / \mathrm{d}(20-80 \mathrm{bbls} / \mathrm{d}$ of liquids).

- The well tests results for the obtained range of gas flow rate in this research for the Pagoreni Field, do not show an increment in the flow rate dependent skin.

- The methodology presented here can be applied in a gas-condensate reservoir with enough information to analyze the fluid flow behavior in the porous medium or in a reservoir with similar characteristics to the Pagoreni Field.

\section{ACKNOWLEDGMENTS}

The authors would like to thank to the Petroleum Engineering Department at the Universidad Nacional de Ingeniería for its kind support. The authors also thank PERUPETRO for providing necessary data.

\section{REFERENCES}

1. Economides, M.J, Dehghani, K., Ogbe, D.O., and Ostermann, R.D. 1987. Hysteresis Effects for Gas Condensate Wells Undergoing Build-up Tests below the Dew Point Pressure. Presented at the $62^{\text {nd }}$ SPE Annual Technical Conference and Exhibition, Dallas, Texas, 27-30 September. SPE-16748. http:// dx.doi.org/10.2118/16748-MS.

2. Bloom, S. M. P., and Hagoort, J. 1998. The Combine effect of Near-Critical Relative Permeability and Non-Darcy Flow on Well Impairment by Condensate Drop-Out. Presented at the SPE Gas Technology Symposium, Canada, 15-18 March. SPE-39976. http://dx.doi.org/10.2118/51367-PA.

3. Yu X., Lei, S., Liangtian, S., and Shilun, L. 1996. A New Method for Predicting the Law of Unsteady Flow Throlugh Porous Medium on Gas Condensate Well. Presented at SPE Program Conference, Canada, 28 April - 1 May. SPE-35649. http://dx.doi. org/10.2118/35649-MS.

4. Gondouin, M., Iffly, R. and Husson, J. 1967. An Attempt to Predict the Time Dependence of Well deliverability in Gas-Condensate Fields. SPE Journal (7): 112-124. SPE-1478-PA. http://dx.doi. org/10.2118/1478-PA.

5. Gringarten, A. C., Bozorgzadeh, M., Daungkaew, S. and Hashemi, A. 2006. Well Test Analysis in Lean Gas Condensate Reservoirs: Theory and Practice. Presented at the SPE Russian Oil and Gas Technical Conference and Exhibition, Moscow, Russia, 3-6 October. SPE-100993. http://dx.doi. org/10.2118/100993-MS.

6. Mott R., Cable A., Spearing M. 2000. Measurements and Simulations of Inertial and High Capillary Number Flow Phenomena in Gas-Condensate Relative Permeability. Presented at the SPE Technical Conference and Exhibition, Dallas, Texas, 1-4 October. SPE-62932-MS. http://dx.doi. org/10.2118/62932-MS. 
7. Fevang, Ø., Whitson, C. H. 1995. Modelling Gas Condensate Well Deliverability. Presented at the SPE Annual Technical Conference and Exhibition, Texas, 22-25 October. SPE-30714. http://dx.doi. org/10.2118/30714-PA.

8. Ali, J. K., McGauley, P. J., and Wilson, C. J. Experimental Studies and Modelling of Gas Condensate Flow Near the Wellbore.1997. Presented at the Fifth Latin American and Caribbean Petroleum Engineering Conference and Exhibition, Brazil, 30 August - 3 September. SPE-39053. http:// dx.doi.org/10.2118/39053-MS.

9. Kalaydjian, F. J-M., Bourbiaux, B. J., Lambard, J-M. 1996. Predicting Gas-Condensate Reservoir Performance: How flow parameters are altered when approaching Production Wells. Presented at the 1996 SPE Annual Conference and Exhibition, Colorado, 6-9 October. SPE-36715. http://dx.doi. org/10.2118/36715-MS.

10. Pope, G. A., Fan, L., Harris B. W., Jamaluddin, A., Kamath J., Mott R., Shandrygin A., Whitson, C. H. 2005. Understanding Gas-Condensate Reservoirs. Oilfield Review 4 (17): 16-29.

11. Sheikhi, E., Hashemi, A., Kaffash, A. 2015. Effect of Non-Darcy Flow Coefficient Variation Due to Water Vaporization on Well Productivity of Gas Condensate Reservoirs. Brazilian Journal of Chemical Engineering 32 (1): 237-245. http://dx.doi. org/10.1590/0104-6632.20150321s00001865.

12. Danesh, A., Tehrani, A. D., Henderson, G. D., AlShaidi, S., Ireland, S., \& Thomson, G. 1997. Gas Condensate Recovery Studies: Relative Permeability and its Impact on Well Productivity. Presented at UK DTI Improved Oil Recovery Research Dissemination Seminar, London, United Kingdom. 18-19 June.

13. Henderson, G. D., Danesh, a, Tehrani, D. H., \& Al-Kharusi, B. 2000. The Relative Significance of Positive Coupling and Inertial Effects on Gas Condensate Relative Permeability at High Velocity. Presented at the SPE Annual Technical Conference and Exhibition, Dallas, Texas, 1-4 October, SPE62933-MS. http://dx.doi.org/10.2118/62933-MS.
14. Jamiolahmady, M., Sohrabi, M., Ireland, S., \& Ghahri, P. 2009. A Generalized Correlation for Predicting Gas-condensate Relative Permeability at near Wellbore Conditions. Journal of Petroleum Science and Engineering 66 (3-4): 98-110. http:// doi.org/10.1016/j.petrol.2009.02.001.

15. Afidick, D., Kaczorowski, N. J., Bette, S. 1994. Production Performance if a Retrograde Gas: A Case Study of the Arun Field. Presented at the SPE Asia Pacific Oil and Gas Conference, Melbourne, Australia, 7-10 November, SPE-28749. http:// dx.doi.org/10.2118/28749-MS.

16. Muskat, M. 1946. The Flow of Homogeneous Fluids through Porous Media, first edition. J. W. Edwards.

17. Forchheimer, P. 1901. Wasserbewegung durch boden, Zeit. Berlin.

18. Fancher, G.H. 1933. Some Physical Characteristics of Oil Sands. Bull. 12, Pennsylvania State C., Minerals Industries Experiment Station, University Park.

19. Geertsma, J. 1974. Estimating the Coefficient of Inertial Resistance in Fluid Flow through Porous Media. SPE Journal 14 (05): 445-450. SPE-4706PA. http://dx.doi.org/10.2118/4706-PA.

20. Katz, D.L., Lee, L.L. 1990. Natural Gas Engineering. New York. McGrawHill

21. Economides, M. J., Hill, A. D., Ehlig-Economides, C. Petroleum Production Systems. New Jersey: Prentice Hall.

22. Guo B., Ghalambor, A. 2005. Natural Gas Engineering Handbook. Houston, TX. Gulf Publishing Company.

23. Mott, S. R., Cable, A., Spearing, S. M. 2000. Measurements and Simulation of Inertial and High Capillary Number Flow Phenomena in GasCondensate Relative Permeability. Presented at the SPE Annual Technical Conference and Exhibition, Dallas, Texas, 1-4 October. SPE-62932. http:// dx.doi.org/10.2118/62932-MS. 
24. Navarro, W.Jamiolahmady, M. 2014. Condensate Banking Study - Pagoreni Field Case. Presented at the VIII INGEPET Conference and Exhibition, Lima, Peru, 3-7 November.

25. Corey, A. T., Rathjens, C. H., Effect of Stratification on Relative Permeability. 1956. Trans. AIME 1956, pp. 207, 358 .

26. Jamiolahmady, M., Danesh, a, Tehrani, D. H. 2003. Positive Effect of Flow Velocity on Gas - Condensate Relative Permeability: Network Modelling and Comparison with Experimental Results. Transport in Porous Media 52 (2): 159183. DOI: 10.1023/A:1023529300395.

\section{NOMENCLATURE}

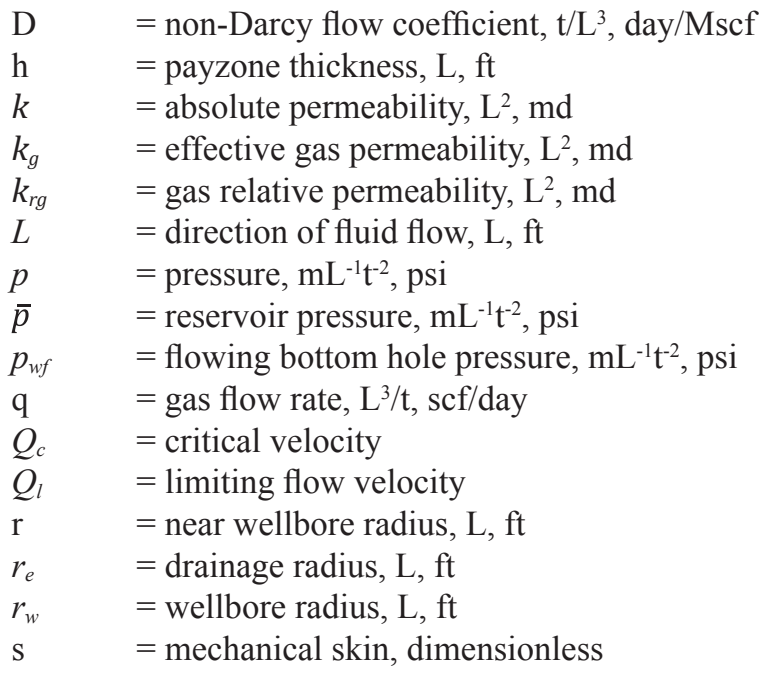

$$
\begin{array}{ll}
S_{g} & =\text { gas saturarion, percentage } \\
\mathrm{s}^{*} & =\text { non/Darcy flow skin, dimensionless } \\
v & =\text { superficial velocity, } \mathrm{Lt}^{-1}, \mathrm{~m} / \text { day }
\end{array}
$$

\section{GREEK LETTERS}

$\beta=$ non-Darcy velocity coefficient, $\mathrm{L}^{-1}, \mathrm{psi}^{2}-\mathrm{md}-\mathrm{ft}-\mathrm{D} /$ Mscf/cp

$\mu=$ viscosity, $\mathrm{m} / \mathrm{Lt}, \mathrm{cp}$

$\rho=$ fluid density, $\mathrm{m} / \mathrm{L}^{3}, \mathrm{~g} / \mathrm{cm}^{3}$

\section{SUBSCRIPT}

$a=$ denotes the intercept of the straight line of the correlation

$b=$ denotes the slope of the straight line of the correlation

\section{ABbREVIATIONS}

$\mathrm{CCE}=$ constant composition expansion

CVD = constant volume depletion

FBHP = flowing bottom hole pressure

IFT $=$ interfacial tension

PVT = pressure-volume-temperature

\section{OPERATORS}

$\Delta \quad=$ difference

$m() \quad=$ real gas pseudopressure 